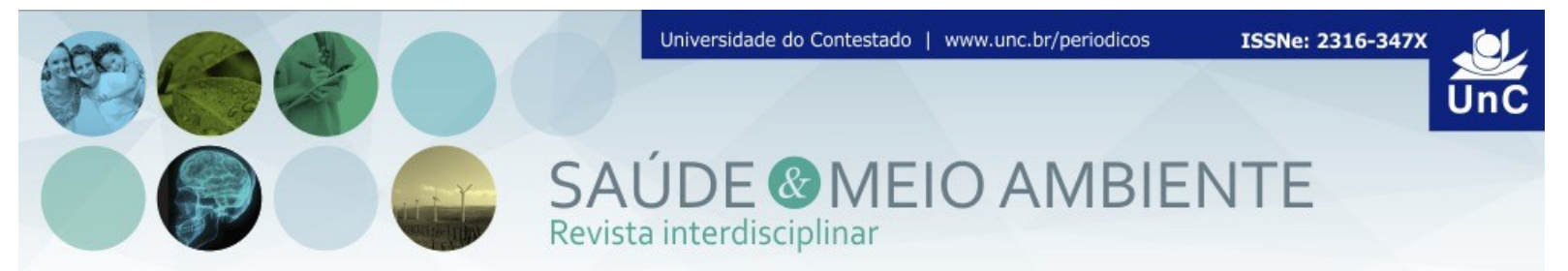

\title{
PERCEPÇÃO AMBIENTAL DOS COLABORADORES SOBRE OS RESÍDUOS NO CAMPUS UNIVERSITÁRIO DE MAFRA/SC ${ }^{1}$
}

\author{
Alessandra Wagner ${ }^{2}$ \\ Halina Linzmeier Heyse ${ }^{3}$
}

RESUMO: A preocupação com a preservação do meio ambiente tem sido um assunto bastante tratado nos últimos anos, principalmente pela grande produção de resíduos sólidos. Esta pesquisa teve como objetivos analisar o conhecimento dos colaboradores da Universidade do Contestado, Campus Mafra/SC, sobre os materiais recicláveis e os resíduos gerados no Campus. Além disso, foi verificada se a utilização das lixeiras está sendo realizada de forma correta conforme sua descrição e cor. A pesquisa foi realizada através de questionários aplicados aos colaboradores e verificação in loco das lixeiras. Os colaboradores apresentaram conhecimento sucinto em relação à reciclagem. Sabem o conceito e as cores relacionadas às lixeiras da coleta seletiva e quais são as categorias referentes a essas cores, entretanto os mesmos ainda confundem os materiais recicláveis e os que não podem ser reaproveitados. Após o levantamento dos dados foi possível ressaltar a importância de programas na área ambiental no ambiente universitário. Uma vez que os colaboradores adquirem conhecimento e ganham nova mentalidade sobre a preservação do meio ambiente, criam novas atitudes tornando-se agentes multiplicadores de boas práticas ambientais.

Palavras chaves: Universidade. Resíduos. Reciclagem.

\section{EMPLOYEES' ENVIRONMENTAL PERCEPTION OF WASTE AT MAFRA CAMPUS / SC}

ABSTRACT: The concern with the preservation of the environment has been a plenty treated subject in the last years, mainly for the great production of solid residues. This research had as objectives to analyze the knowledge of Contestado University collaborators, at campus Mafra/SC about recycled materials and the residues generated in the campus. Besides, the use of the trash cans was verified it is being accomplished in a correct way according to its description and color. The research was accomplished through questionnaires applied to the collaborators and verification in loco of collaborating trash cans. The collaborators presented brief knowledge in relation to the recycling. They know the concept and the colors related

\footnotetext{
${ }^{1}$ Artigo elaborado a partir da pesquisa, apresentado na Pós-Graduação em Gestão e Auditoria Ambiental, Universidade do Contestado (UnC) - Campus Universitário de Mafra.

${ }^{2}$ Pós-Graduada em Gestão e Auditoria Ambiental - Universidade do Contestado (UnC) - Campus Universitário de Mafra. E-mail: ssandraw@yahoo.com.br

${ }^{3}$ Professora Orientadora da UnC - Universidade do Contestado (UnC)- Campus Universitário de Mafra. Mestre em Ecologia e Conservação pela Universidade Federal do Paraná (UFPR). E-mail: haliheyse@gmail.com
} 
to the trash cans of the selective collection and which are the referring categories to those colors, however the same ones still confuse the materials you recycled and the ones that cannot be recycled. After the rising of the data it was possible to stand out the importance of programs in the environmental area in the university atmosphere. Once the collaborators acquire knowledge and they get a new mentality about the preservation of the environment, they create new attitudes becoming multipliers agents of good environmental practices.

Keywords: University. Waste. Recycling.

\section{INTRODUÇÃO}

Uma grande preocupação na atualidade é a crescente produção de resíduos sólidos a qual contribui para destruição do meio ambiente. Em todas as atividades econômicas há geração contínua de resíduos, inclusive nas Universidades. Nestas instituições deve ser observado se há o descarte adequado dos resíduos, pois seu gerenciamento é de extrema importância.

Os resíduos sólidos são os restos sólido-semissólidos gerados durante as atividades econômicas e sociais. A forma inadequada de deposição desses resíduos a céu aberto acaba gerando a poluição do solo, ar e água, além de causar a proliferação de transmissores de doenças. Desta forma, surgiram formas de controle desta geração desenfreada de resíduos (ZANTA; FERREIRA, 2014).

Em 1992 a ONU realizou a Conferência de Desenvolvimento e Meio Ambiente das Nações Unidas conhecida como ECO 92, a qual discutia como o mundo poderia mudar em direção ao desenvolvimento sustentável. Nesta conferência foram produzidos importantes documentos, sendo um deles a Agenda 21. Este documento procura um consenso global e compromisso político do mais elevado nível contribuindo para a solução dos problemas ambientais e buscando o desenvolvimento futuro de forma sustentável (MALHEIROS; PHILIPPI JUNIOR; COUTINHO, 2008).

No ano de 2010 foi criada a Política Nacional de Resíduos Sólidos (Lei N $12.305 / 10)$, a qual prevê a prevenção e a redução na geração de resíduos. Nela estão instrumentos importantes para a redução dos principais problemas ambientais, sociais e econômicos provenientes do manejo inadequado dos resíduos sólidos. Com a crescente geração desses resíduos foi necessário elaborar uma gestão dos resíduos sólidos que trata do controle, armazenamento, coleta, transporte, processamento, tratamento e do destino final dos resíduos (RUSSO, 2003).

No Brasil a gestão dos resíduos sólidos é de competência dos municípios. A maior parte dos resíduos originados em nosso país não é coletada regularmente (MONTEIRO, 2001). Estes são dispostos em terrenos baldios, encostas e cursos d'água, geralmente em áreas/cidades de baixa renda. 
Uma das atividades que pode ser incluída nos sistemas de gerenciamento dos resíduos é a reciclagem. Segundo a Política Nacional de Resíduos Sólidos (Lei $\left.N^{0} 12.305 / 10\right)$, a reciclagem é um processo de modificação dos resíduos, onde são alteradas suas propriedades físicas, físico-químicas ou ainda biológicas, transformando estes em novos produtos em novas formas de consumo.

A reciclagem é uma técnica essencial na preservação do meio ambiente, pois atua na redução do acúmulo de resíduos gerando benefícios significativos para nossa sociedade. Uma forma de contribuir é a implantação da política dos 3R's, que integra um conjunto de medidas onde: é preciso reduzir a geração de resíduos através do consumo sustentável; reutilizar, começando com novos produtos, que possam ser utilizados para outros fins; e reciclar, o qual pode render lucros para empresas e catadores, onde fazem a coleta seletiva e todo o processo de reciclagem (CAMPOS, 2012).

As universidades e Instituições de Ensino Superior (IES) têm grande papel perante a sociedade, seja de ordem social, política, econômica e cultural. Têm a incumbência de apresentar aos seus alunos os problemas que a sociedade possui e dessa forma contribuir para que possam encontrar soluções viáveis (REIS; BANDOS, 2012).

Além disso, estas instituições devem sempre buscar melhorias e comprometer-se com a prevenção e conservação do meio ambiente. Há duas formas de pensamento referentes à função das universidades e IES no que diz respeito ao desenvolvimento sustentável. A primeira refere-se à questão educacional, que contribui na qualificação de seus alunos em suas práticas profissionais relacionadas às questões ambientais. A segunda diz respeito à atitude das IES na implementação de sistemas de gestão ambiental em seus Campi universitários, servindo como exemplos para a sociedade (TAUCHEN; BRANDLI, 2006).

As Universidades são vistas como bases na educação ambiental, desta forma devem conter planos de gerenciamentos de seus próprios resíduos. Nestes devem ser incluídos a coleta seletiva dos materiais recicláveis e o descarte adequado dos resíduos que não podem ser reaproveitados.

A Universidade do Contestado Campus Mafra/SC (UnC/Mafra) possui o programa "UnC - Recicle" que busca informar, sistematizar , educar, sensibilizar e conscientizar sua comunidade acadêmica sobre o uso dos materiais e da produção do lixo. Através de ações que buscam a redução da produção de lixo, reutilização dos produtos e materiais e a reciclagem como forma alternativa de tratamento do lixo são desenvolvidas ações dentro do Campus (UNIVERSIDADE DO CONTESTADO, 2008). Porém, durante a vigência da pesquisa tal programa encontrava-se desativado.

O objetivo geral do trabalho foi verificar a percepção ambiental dos colaboradores sobre os resíduos na Universidade do Contestado, campus de Mafra. Os objetivos específicos foram analisar o conhecimento dos funcionários sobre as classes de materiais recicláveis e verificar se as lixeiras estão sendo utilizadas de 
forma correta conforme sua descrição e cor. Desta forma buscamos contribuir para futuras ações de educação ambiental no campus baseadas neste conhecimento dos colaboradores da instituição.

\section{MATERIAIS E MÉTODOS}

Foi realizada pesquisa bibliográfica e aplicação de questionários para os colaboradores (professores, técnicos administrativos e auxiliares de manutenção) da Universidade do Contestado, Campus Mafra- SC (UnC/Mafra). A UnC/Mafra contém 13 cursos de graduação e 6 cursos de pós-graduação, compreende 272 professores, 121 funcionários e aproximadamente 2.300 acadêmicos, totalizando 2.693 pessoas utilizando o ambiente universitário. Nos espaços de convivência da universidade há 55 lixeiras de resíduos gerais e coleta seletiva, distribuídas entre o bloco A e o bloco G. O questionário aplicado apresentava 14 questões de múltipla escolha e uma questão discursiva optativa que verificaram o conhecimento dos funcionários em relação aos resíduos. A amostra foi constituída de 59 colaboradores aleatórios de todos os setores da UnC/Mafra, pois são os funcionários que passam mais tempo na instituição, julgando-se mais relevantes para a pesquisa. A pesquisa seguiu os preceitos éticos em todas as etapas de seu desenvolvimento.

\section{RESULTADOS E DISCUSSÕES}

As universidades precisam inteirar-se dos problemas sociais, como por exemplo, aqueles relativos ao meio ambiente buscando transmitir suas contribuições à sociedade. Esta pesquisa apontou o conhecimento que os colaboradores apresentam em relação à reciclagem. Desta forma foi possível verificar um conhecimento sucinto e a importante contribuição de programas de educação ambiental à universidade e seus colaboradores.

As universidades, por serem grandes construtoras de conhecimento e formadora de profissionais, contribuem muito com a responsabilidade social e ambiental (REIS; BANDOS, 2012). Essas instituições necessitam que seus funcionários tenham conhecimento e responsabilidades em relação ao meio ambiente, contribuindo assim na educação dos alunos que frequentam as IES. A educação ambiental atua como uma ferramenta básica para a sustentabilidade dos processos de gestão. Desta forma é importante que o educador demonstre as interações entre sociedade-natureza através dos aspectos sociais, culturais e políticos (ZANETI, 2003).

A educação ambiental é um fator indispensável na gestão de resíduos. Busca uma mudança de atitudes auxiliando o processo educativo crítico, conscientizador e contextualizado, servindo como ferramenta de reflexão em relação ao descarte 
apropriado do lixo e valorizando o meio ambiente (FERREIRA; PROCOPIAK; CUBAS, 2011). É necessário conhecer a percepção dos colaboradores sobre a reciclagem para posteriormente aplicar os projetos em seus locais de trabalho. A maioria dos colaboradores $(93,22 \%)$ da Universidade do Contestado - Campus Mafra/SC conhece a definição de reciclagem (Figura 1). Para os demais colaboradores $(6,77 \%)$ a reciclagem é o estudo do reaproveitamento de materiais inertes.

Figura 1 - Significado do termo reciclagem.

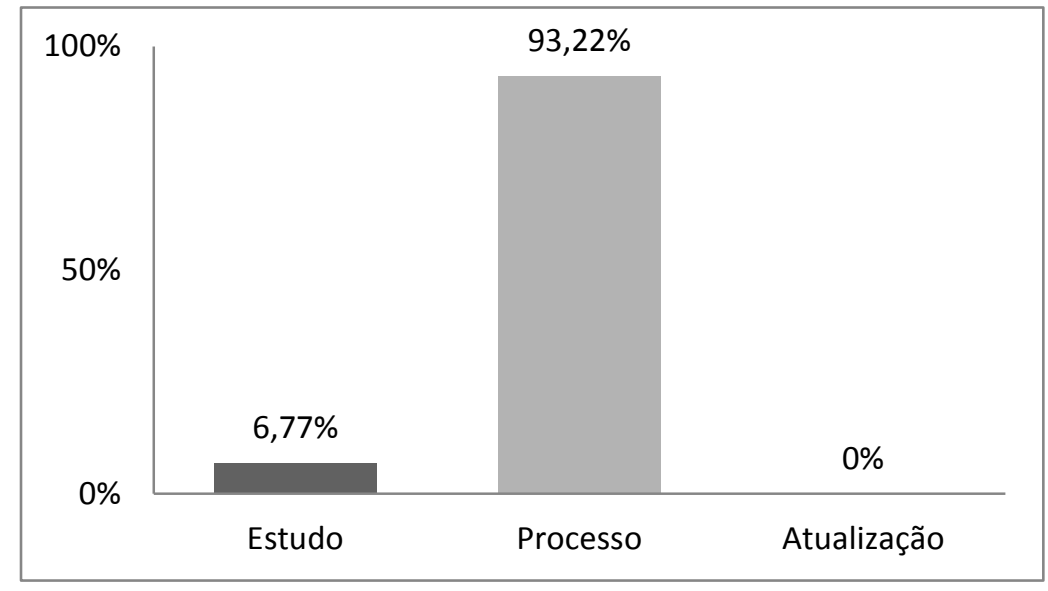

Onde: Estudo $=\mathrm{A}$ reciclagem é o estudo do reaproveitamento de materiais inertes; Processo $=\mathrm{A}$ reciclagem é o processo de transformação de materiais já utilizados em novos produtos; e, Atualização = Reciclar é uma forma de se atualizar na vida profissional.

Podemos verificar há uma lacuna no conhecimento dos materiais que são recicláveis (Figura 2). Nem todos os tipos de papeis podem ser reciclados, exemplo disso são os guardanapos, lenço de papel, papeis plastificados, papel vegetal e fotografias. Outros materias não recicláveis que foram assinalados foram: grampos de grampeadores e fitas adesivas. Portanto, há a necessidade de campanhas, palestras e capacitações sobre este tema direcionadas aos colaboradores. Assim, os funcionários da instituição agregarão maior conhecimento sobre a reciclagem dos materiais e isto contribuirá para uma gestão ambiental mais efetiva. 
Figura 2 - Materiais considerados recicláveis pelos colaboradores.

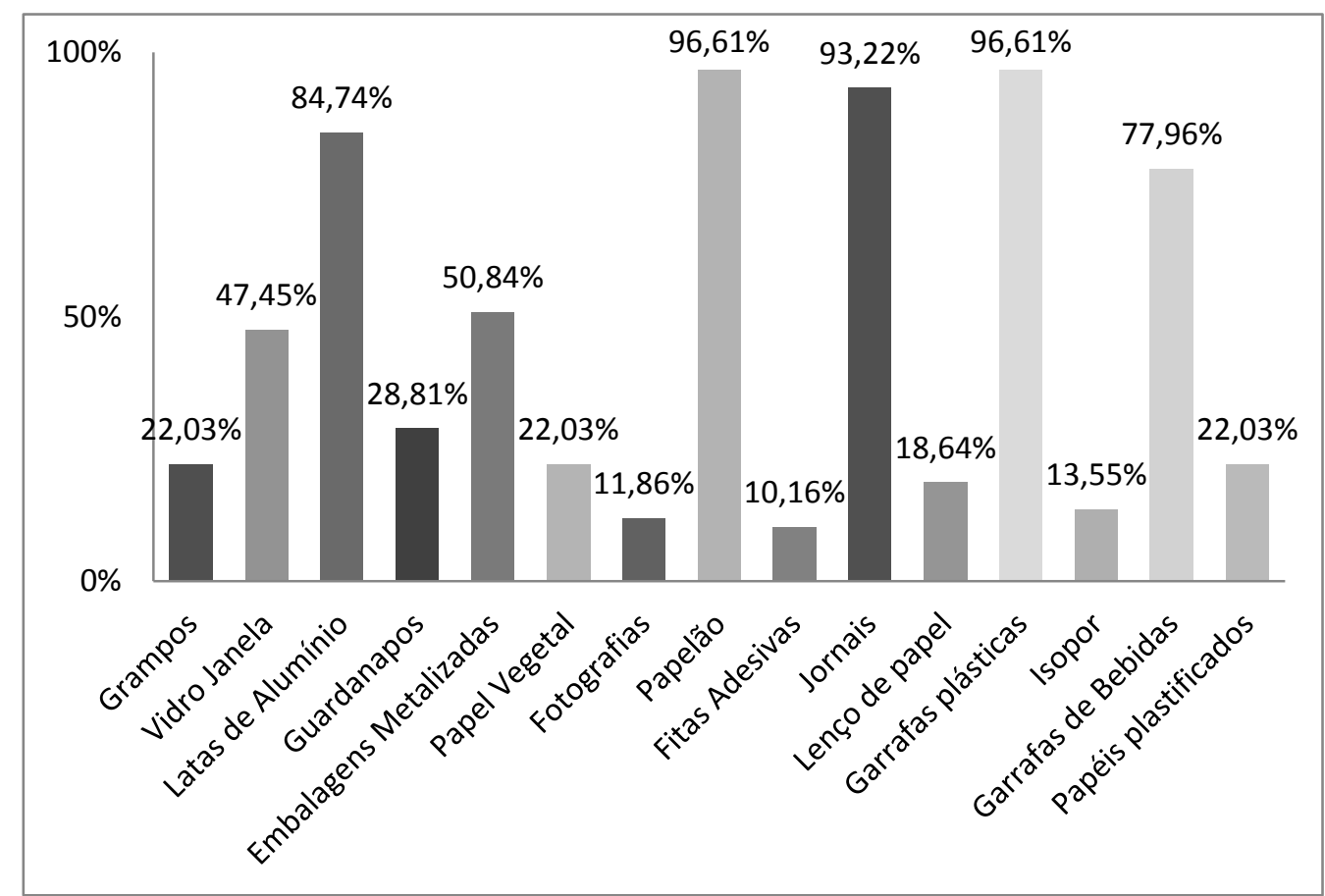

Com relação às cores das lixeiras e seus resíduos associados, a maior parte dos colaboradores conhece as cores corretas de destinação para cada tipo de resíduo (Figura 3). O Campus possui em todos os blocos as lixeiras com as cores e descrição do material que deve ser descartado como papeis plásticos, vidros, metais e resíduos gerais, o que facilita aos funcionários fixarem as cores. É de extrema importância que a universidade mantenha as lixeiras por todo o campus para que as pessoas cada vez mais busquem separar os resíduos gerados conforme sua categoria. Estes devem ser previamente separados na fonte geradora para que o sistema de recolhimento seja eficaz. A coleta seletiva colabora no processo de educação ambiental, uma vez que ajuda na sensibilização da comunidade a respeito dos desperdícios dos recursos naturais e da poluição acarretada pelo lixo (SÃO PAULO, 2013). 
Figura 3 - Conhecimento dos colaboradores referente aos resíduos classificados conforme a cor da lixeira.

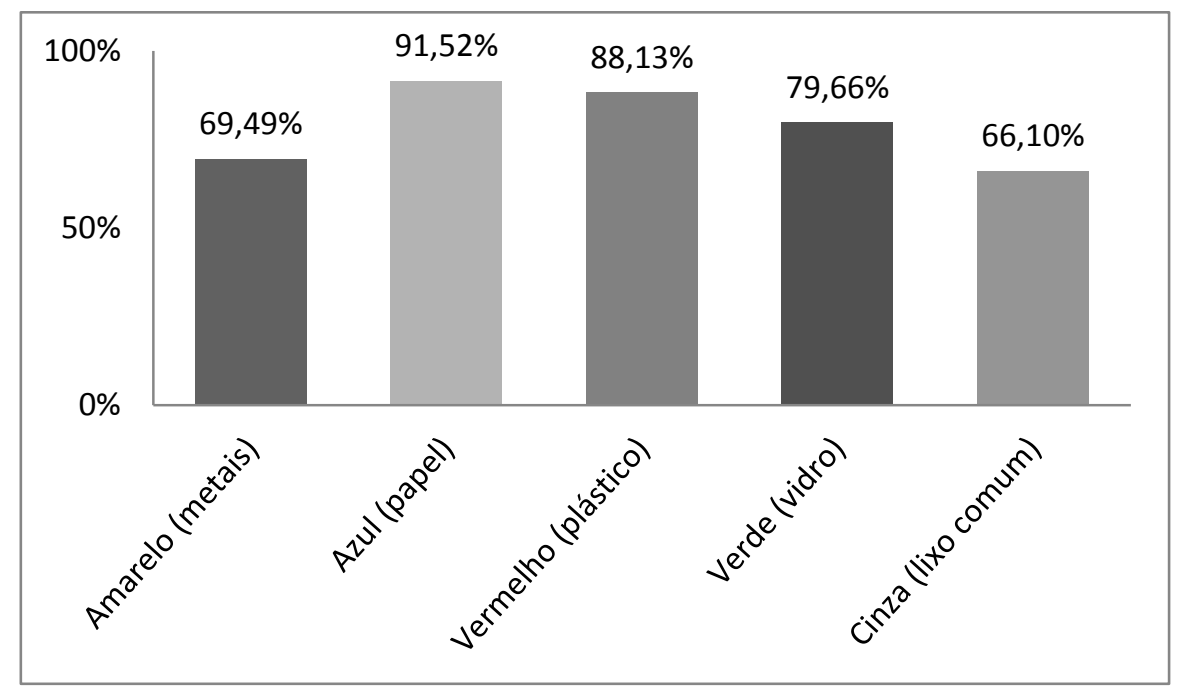

Outro aspecto questionado referia-se ao princípio dos 3 R's, apresentado na Agenda 21: redução (do uso de matérias-primas e energia e do desperdício nas fontes geradoras), reutilização direta dos produtos e reciclagem de materiais (BRASIL, 1995). A maior parte dos pesquisados (83,05\%) respondeu corretamente (Figura 4). Um caminho para a solução dos problemas relacionados com o lixo é apontado por este Princípio dos 3 R's - Reduzir, Reutilizar e Reciclar. Isto precisa ser considerado nos projetos institucionais, já que é ideal para a busca de padrões de consumo sustentável. O projeto UnC recicle desfruta desse princípio através do uso racional de bens, equipamentos, insumos os quais são utilizados no decorrer do trabalho. Assim há uma contribuição na conservação dos recursos naturais (BRASIL, 2014).

Figura 4 - Conceito dos três R's da reciclagem.

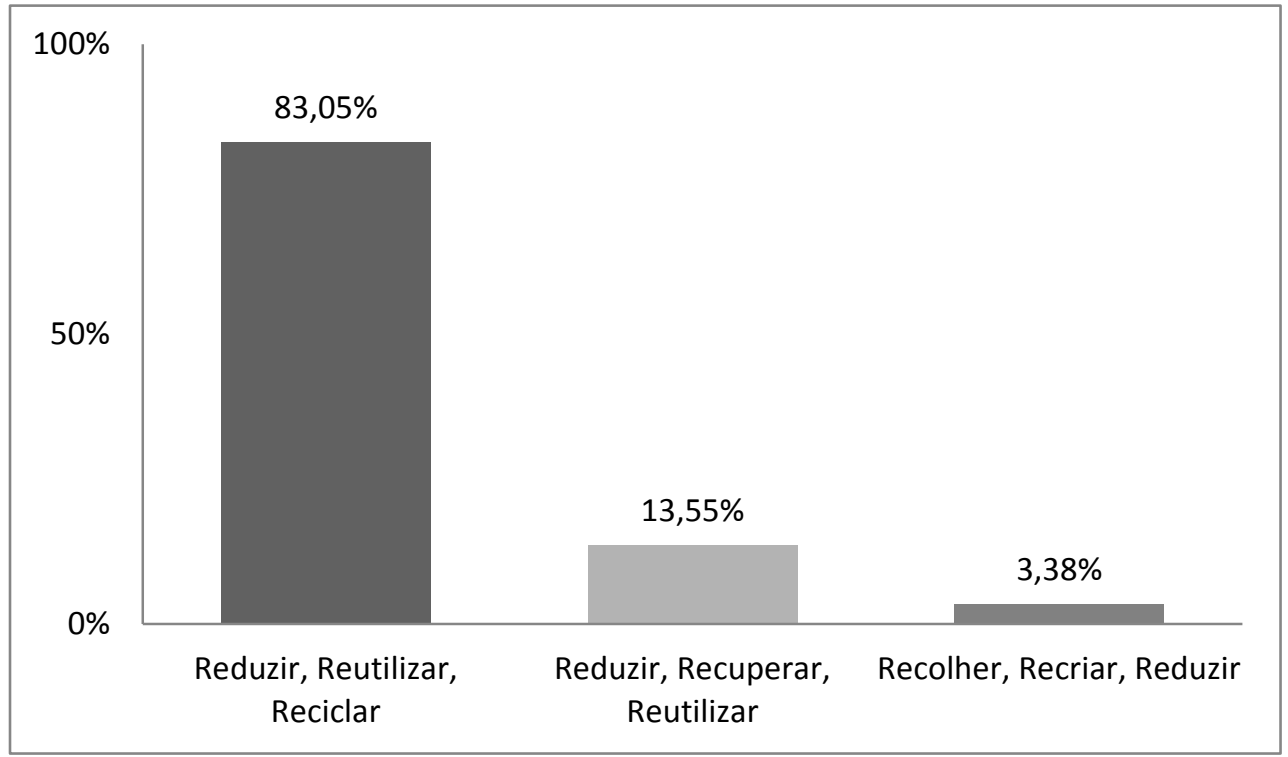


A geração de resíduos sólidos, principalmente os orgânicos, têm crescido bastante. Os resíduos orgânicos têm grande capacidade de atrair vetores e sua decomposição gera um líquido altamente poluidor, o chorume (CARVALHO et al., 2012). Não há, coleta, transporte, tratamento e destinação apropriados a esse tipo de resíduo na maior parte dos municípios brasileiros. Uma forma de reaproveitar os rejeitos orgânicos é através da compostagem, a qual consiste de um processo biológico de decomposição que resulta em um produto igual ao húmus (OLIVEIRA, 1997). O processo da compostagem pode ser utilizado em hortas, através dos princípios da educação ambiental e por meio de um processo educativo, procura impulsionar o desenvolvimento sustentável. A maioria dos colaboradores $(98,30 \%)$, relacionou a reciclagem da matéria orgânica com a compostagem (Figura 5).

Figura 5 - Reciclagem da matéria orgânica

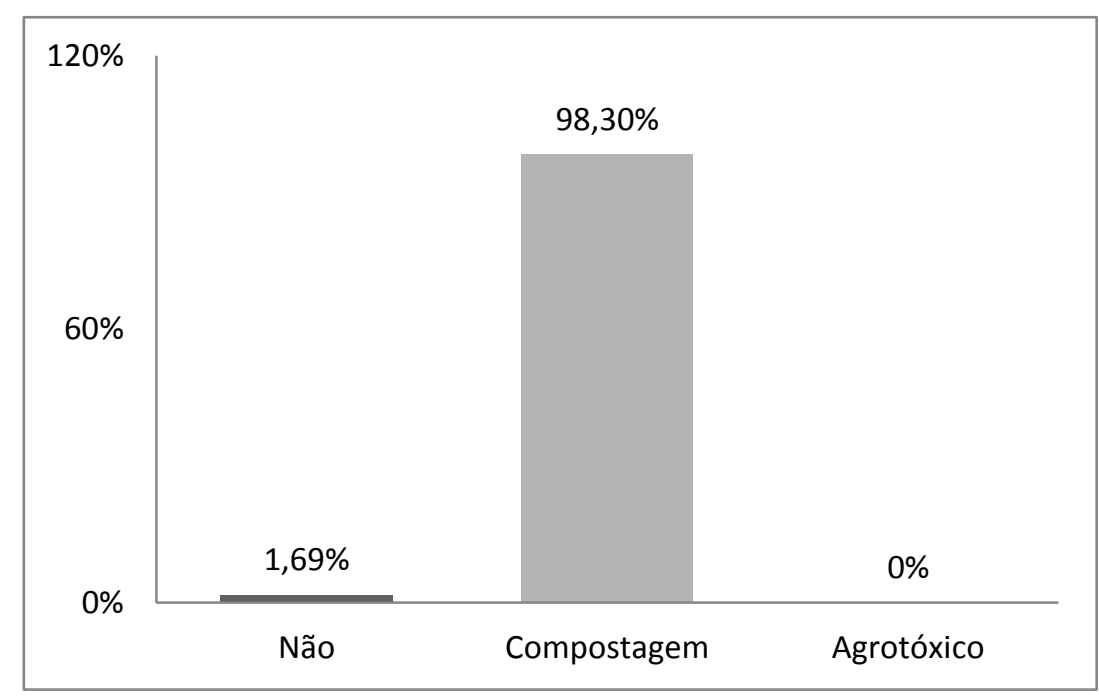

Onde: Não = Este tipo de material não tem como ser reaproveitado; Compostagem = Com este material faz a compostagem, que se transforma em adubo; Agrotóxico = A matéria orgânica, depois de consumida, é utilizada como agrotóxico.

A maior parte dos colaboradores $(61,01 \%)$ não sabe para onde vão os resíduos após a coleta realizada pelos responsáveis da manutenção dos setores (Figura 6). Os resíduos produzidos na universidade têm como destino a empresa de reciclagem, porém, muitos materiais ainda acabam tendo como destino o lixo comum. 
Figura 6 - Conhecimento dos colaboradores sobre o destino final dos resíudos gerados no setor.

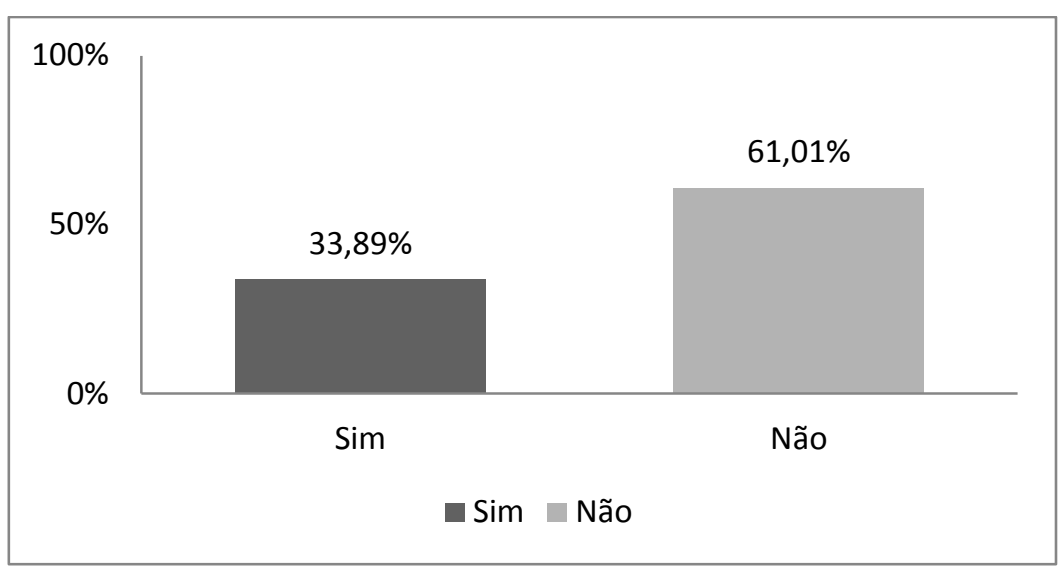

Onde: $\operatorname{Sim}=$ conhece $\mathrm{o}$ destino final dos resíduos; Não = não conhece o destino final dos resíduos .

Para a maior parte dos funcionários $(69,49 \%)$ não há lixeiras nos setores para todas as classes de materiais produzidos durante o trabalho. Verifica-se desta forma, que há a necessidade de haver mais lixeiras para diferentes tipos de resíduos, inclusive os orgânicos, pois só existem para resíduos gerais. O ideal para uma boa gestão de resíduos é instituir elo entre os comportamentos dos diversos setores para que o mesmo funcione como um sistema (FERREIRA; PROCOPIAK; CUBAS, 2011).

Além das perguntas foram solicitadas sugestões para melhorar a gestão dos resíduos na UnC/Mafra, onde destaca-se a reativação do programa UnC/Recicle. $\mathrm{O}$ programa é de extrema importância, pois envolve todos os funcionários dos setores da UnC/Mafra fazendo com que adotem a postura de agentes comprometidos com o uso racional dos recursos materiais que Ihes são disponibilizados. Como, por exemplo, o reaproveitamento de papeis, transformando em blocos de anotações; evitar adquirir produtos com embalagens que não são biodegradáveis; diminuir o uso de copos descartáveis; entre outras ações.

Os tipos de lixeiras encontrados nas dependências da UnC/Mafra, sendo estas de coleta seletiva, resíduos gerais e ainda lixeiras para as pontas de cigarro, estão ilustrados na Figura 7. A Figura 8 demostra o número de lixeiras distribuídas na universidade. Durante a contagem das lixeiras foi observado se o seu uso estava sendo realizado corretamente. Contudo foi averiguado que nas lixeiras da coleta seletiva os resíduos são dispostos no mesmo lixeiro, não ocorrendo a devida seleção dos materiais. A separação do lixo é de extrema importância, pois facilita a coleta e o encaminhamento para os locais de reciclagem. (SÃO PAULO, 2013). 
Figura 7 - (A) Lixeiras utilizada para coleta de resíduos gerais. (B) Lixeiras utilizadas para resíduos e gerais e coleta de pontas de cigarro. (C) Lixeiras da coleta seletiva.
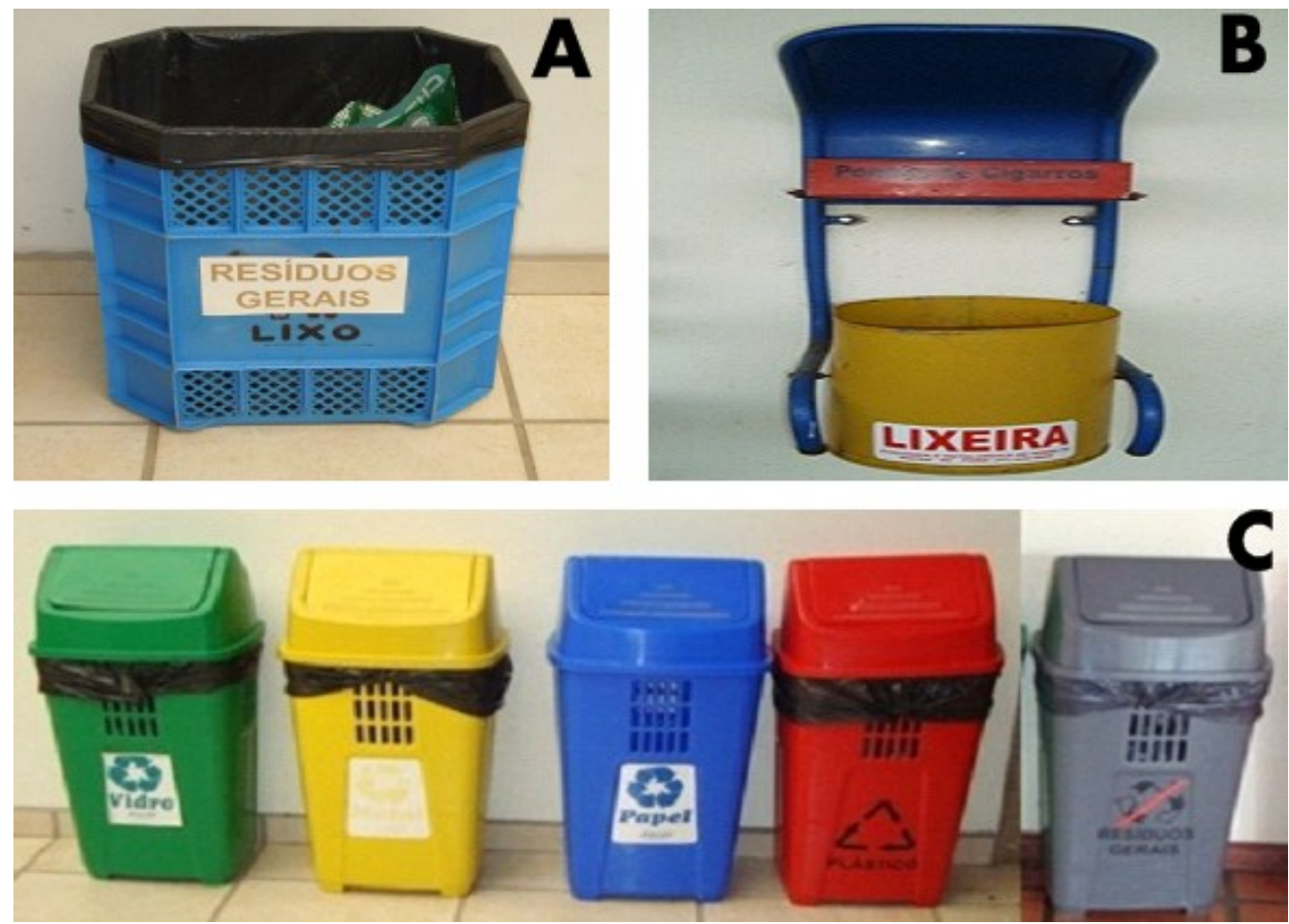

Figura 8 - Demonstrativo das lixeiras distribuídas na Universidade do Contestado - campus Mafra/SC.

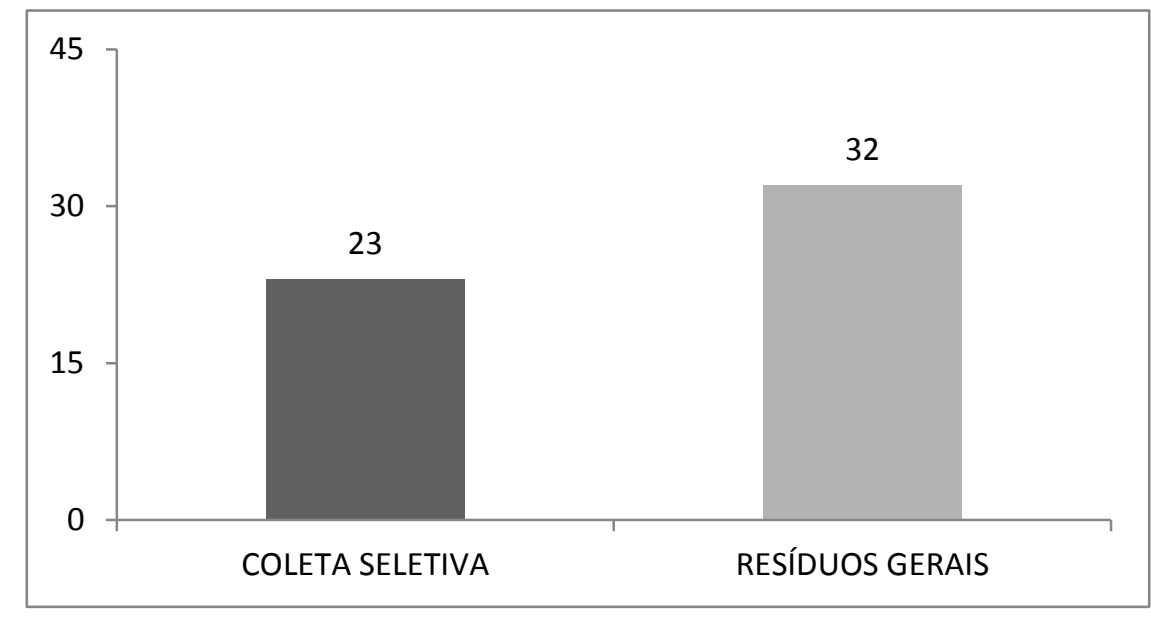

\section{CONSIDERAÇÕES FINAIS}

A reciclagem propicia expressivos resultados no ambiente, na sociedade e também na economia. Ambientalmente há a diminuição de resíduos gerados e ocorre o reaproveitamento dos mesmos. Economicamente há uma redução nos custos produtivos e na geração de empregos. Já para a sociedade há maior qualidade de vida. (ANDRADE, 2010). 
Após a implementação da pesquisa na Universidade do Contestado, Campus Universitário de Mafra/SC, constatou-se que os colaboradores têm um conhecimento básico de reciclagem. Para eles, a reciclagem reduz a quantidade de resíduos e de matéria prima utilizada. São necessários programas de educação ambiental mais frequentes que abordem a temática dos resíduos para que sejam encontrados resultados mais significativos.

Os colaboradores conhecem as cores relacionadas às lixeiras da coleta seletiva, porém ainda tem dificuldades para identificar quais os materiais podem ser reciclados. Desta forma, inserir a educação ambiental no ambiente universitário tem como objetivo transformar as universidades e Instituições de Ensino Superior (IES) como modelos de gestão sustentável à sociedade.

Foi possível ressaltar a importância dos programas na área ambiental no campus, uma vez que é um local onde há a qualificação e transformação dos acadêmicos em profissionais. As universidades devem apresentar projetos e um sistema de gerenciamento de seus resíduos que incluam as práticas sustentáveis e sirvam de exemplo para a sociedade. A reimplantação do programa UnC/Recicle possibilitaria uma melhoria para o Campus, transmitindo para seus colaboradores orientações, tirando dúvidas e inserindo maneiras adequadas para a coleta seletiva. Conceitos como reduzir, reutilizar e reciclar devem ser frequentes no ambiente de trabalho e os resíduos gerados separados de maneira correta. Além disso, todas estas informações poderiam ser repassadas aos acadêmicos da universidade aumentando a área de abrangência do projeto e efetivando o papel transformador da instituição na sociedade.

\section{REFERÊNCIAS}

ANDRADE, Rodrigo Ferreira. Reciclagem: sua importância e impacto econômico e ambiental. 17 dez. 2010. In: ADMINISTRADORES: o portal da Administração. Artigos, João Pessoa, 2010. Disponível em: <http://www.administradores.com.br/ artigos/marketing/reciclagem-sua-importancia-e-impacto-economico-eambiental/50722/>. Acesso em: 06 mar. 2014.

BRASIL. Câmara Dos Deputados. Agenda 21. Brasília: Centro de Documentação e Informação, 1995. Disponível em: <http://www.onu.org.br/ rio20/img/2012/01/agenda21.pdf>. Acesso em: 18 abr. 2014.

BRASIL. Lei n. 12.305, de 02 de agosto de 2010. Institui a Política Nacional de Resíduos Sólidos; altera a Lei n. 9.605, de 12 de fevereiro de 1998; e dá outras providências. Disponível em: <http://www.planalto.gov.br/ccivil_03/_ato20072010/2010/lei//12305.htm>. Acesso em: 15 nov. 2013.

BRASIL. Ministério do Meio Ambiente. Princípio dos 3R's. Disponível em: <http://www.mma.gov.br/component/k2/item/7589-princípio-dos-3r-s>. Acesso em: 18 abr. 2014. 
CAMPOS, T.H.K. Renda e evolução da geração per capita de resíduos no Brasil. Engenharia sanitária ambiental, Rio de Janeiro, v. 17, n. 2, abr./jun. 2012. Disponível em: <http://www.scielo.br>. Acesso em: 23 jul. 2014.

CARVALHO, R. R. et al. A compostagem como ferramenta de educação ambiental no Instituto Federal do Maranhão campus Codó. In: CONGRESSO NORTE NORDESTE DE PESQUISA E INOVAÇÃO (CONNEPI), 7., 19 a 21 out. 2012. Anais... Palmas, 2012. Disponível em: <http://propi.ifto.edu.br/ocs/ index.php/connepi/vii/paper/viewFile/5080/1730>. Acesso em: 01 abr. 2014.

FERREIRA, Fernanda Tiemi Nakashima; PROCOPIAK, Letícia Knechtel; CUBAS, Karina Guedes. O conhecimento sobre resíduos sólidos das funcionárias de serviços gerais de uma universidade do município de Curitiba. In: CONGRESSO BRASILEIRO DE GESTÃO AMBIENTAL, 2.. 06 a 09 nov. 2011. Anais... Londrina, PR: Campus Piza, Unopar, 2011. Disponível em: <http://www.ibeas.org.br/congresso/Trabalhos2011/III-017.pdf>. Acesso em: 01 maio 2014.

LOCH, L.; DAY, B. C.; JAEGER, E. V. Os resíduos sólidos e a relação com a educação ambiental em uma escola pública do Alto Vale (SC). REAVI, Alto Vale Itajaí, v. 2, n. 1. p. 10-21, ago. 2013. Disponível em: <http://www.revistas. udesc.br/index.php/reavi/article/view/3442/2552>. Acesso em: 18 abr. 2014.

MALHEIRO, T.F.; PHLIPPI JR. A.; COUTINHO, S.M.V. Agenda 21 nacional e indicadores de desenvolvimento sustentável: contexto brasileiro. Saúde e Sociedade, São Paulo, v. 17, n. 1, p. 7-20, jan./mar. 2008. Disponível em: $<$ http://www.scielo.br/scielo.php?script=sci_arttext\&pid=S0104$12902008000100002 \&$ Ing=en\&nrm=iso>. Acesso em: 23 jul. 2014.

MONTEIRO, José Henrique Penido et al. Manual de gerenciamento Integrado de resíduos sólidos. Rio de Janeiro: IBAM, 2001. Disponível em:

<http://www.resol.com.br/cartilha4/manual.pdf>. Acesso em 16 abr. 2014.

OLIVEIRA, Selene de. Gestão dos resíduos sólidos urbanos na microrregião homogênea serra de Botucatu: caracterização física dos resíduos sólidos domésticos na cidade de Botucatu/SP. 1997. 138 f. Dissertação (Mestrado em Agronomia) - Universidade Estadual Paulista, Faculdade de Ciências Agronômicas. Botucatu, SP, 1997. Disponível em: <http://www.athena.biblioteca.unesp.br/ exlibris/bd/bla/33004064021P7/1997/oliveira_s_me_botfca.pdf>. Acesso em: 16 abr. 2014.

REIS, Amanda Lima; BANDOS, Melissa Franchini Cavalcanti. A responsabilidade social de instituições de ensino superior: uma reflexão sistêmica tendo em vista o desenvolvimento. Revista Gestão e Conhecimento, Poços de Caldas, MG, ed. esp., p. 423-432, nov. 2012. Disponível em: <http://www.pucpcaldas.br/graduacao/ administracao/revista/ artigos/esp1_8cbs/25.pdf>. Acesso em: 09 maio 2014.

RUSSO, Mário Augusto Tavares. Tratamento de resíduos sólidos. Coimbra: Universidade de Coimbra, 2003. Disponível em: <http://homepage.ufp.pt/ madinis/RSol/Web/TARS.pdf>. Acesso em: 18 nov. 2013. 
SÃO PAULO (Estado). Secretaria do Meio Ambiente. Coleta seletiva: na escola, no condomínio, na empresa, na comunidade, no município. 2.ed. São Paulo: Secretaria do Meio Ambiente, Coordenadoria de Educação Ambiental, 2013. Disponível em: $<$ http://www.ambiente.sp.gov.br/cea/files/2013/09/coleta-seletiva.pdf $>$. Acesso em: 18 abr. 2014.

TAUCHEN, J.; BRANDLI, L. L. A gestão ambiental em instituições de ensino superior: modelo para implantação em campus universitário. Gestão e Produção, v. 13, n. 3, p. 503-515, set./dez. 2006. Disponível em: <http://www.scielo.br>. Acesso em: 05 mar. 2014.

UNIVERSIDADE DO CONTESTADO (UnC). Programa recicle: um novo conceito na UnC. Mafra: UnC, 2008.

ZANETI, Izabel Cristina Bruno Bacellar. Educação ambiental, resíduos sólidos urbanos e sustentabilidade: um estudo de caso sobre o sistema de gestão de Porto Alegre, RS. Brasília. 2003. 176 f. Tese (Doutorado em Desenvolvimento Sustentável) - Universidade de Brasília. Centro de Desenvolvimento Sustentável, Brasília. 2003.

ZANTA, Viviana Maria; FERREIRA, Cynthia Fantoni Alves. Gerenciamento integrado de resíduos sólidos urbanos. In: CASTILHOS JUNIOR, Armando Borges de (Coord.). Alternativas de disposição de resíduos sólidos urbanos para pequenas comunidades. Rio de Janeiro : ABES; RiMa, 2003. Disponível em:

<http://etg.ufmg.br/ gustavo/arquivos/livroprosab.pdf>. Acesso em: 24 maio 2014.

Artigo recebido em: 05/03/2015

Artigo aprovado em: 25/11/2015 